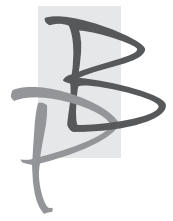

Andrzej Baranow*

Uniwersytet w Białymstoku

https://orcid.org/0000-0003-4787-5384

\title{
Międzynarodowa Interdyscyplinarna Konferencja Naukowa „Nauki humanistyczne w erze globalizacji" Kutaisi, 1-2 listopada 2019. Sprawozdanie
}

W dniach 1-2 listopada 2019 roku w Kutaisi obradowała Międzynarodowa Konferencja Naukowa „Nauki humanistyczne w erze globalizacji”, zorganizowana przez jedną z najważniejszych uczelni gruzińskich, Uniwersytet Państwowy im. Akakiego Ceretelego ${ }^{1}$. Impreza miała charakter międzynarodowy, jej dokumenty tworzone były równolegle w języku gruzińskim i angielskim. Trzeba od razu podkreślić, iż spotkanie to raczej należałoby nazwać międzynarodowym i zarazem ogólnogruzińskim kongresem humanistów, reprezentujących tak bliskie, a zarazem odmienne dyscypliny, jak filologia (od angielskiej po rosyjską, polską), archeologia, filozofia, prawo, psychologia, ekonomia. Gruzja jest stosunkowo niewielkim krajem (7 mln mieszkańców), a konferencje naukowe mają tu charakter zjazdów badaczy z różnych dziedzin.

* Andrzej Baranow - dr hab., prof. UwB; kierownik Pracowni Komparatystyki Kulturowej na Wydziale Filologicznym Uniwersytetu w Białymstoku; przez lata pracował na Litewskim Uniwersytecie Edukologicznym w Wilnie (obecnie: Akademia Edukacji Uniwersytetu Witolda Wielkiego w Kownie, oddział w Wilnie).

1 Uniwersytet Państwowy im. Akakiego Ceretelego to jeden z największych uniwersytetów w Gruzji. Powstał w 1930 roku, w czasach sowieckich został (1933) przekształcony w Państwowy Instytut Pedagogiczny. Rangę uniwersytecką i obecną nazwę nadano uczelni w 1990 roku. Na uczelni istnieje dziewięć wydziałów, w tym pedagogiczny, humanistyczny i prawa. Patron uczelni, Akaki Cereteli (1840-1915), wywodzący się z książęcego rodu gruzińskiego, był twórcą nowoczesnego języka literackiego, pisarzem, działaczem niepodległościowym, absolwentem gimazjum w Kutaisi. 
To naukowe spotkanie zostało bardzo dobrze przygotowane. Organizatorzy ułożyli bogaty Program², w którym zmieściło się około dwustu wystąpień badaczy z takich krajów, jak: Gruzja, USA, Niemcy, Hiszpania, Polska, Ukraina, Litwa, Azerbejdżan, Francja, Bułgaria, Tajwan, Portugalia, Nigeria, Słowacja, Indie, Austria. Zdecydowanie najliczniejsze delegacje przysłały jednak Gruzja (jej badacze dominowali liczebnie), USA, Niemcy, Polska i Słowacja. Nad przygotowaniem kongresu pracował Komitet Organizacyjny złożony z badaczy zatrudnionych na Uniwersytecie w Kutaisi ${ }^{3}$. Przygotowano również specjalną księgę zawierającą wielojęzyczne streszczenia większości wystąpień.

Jak to bywało i bywa na konferencjach wschodnioeuropejskich, szczególnie okazały charakter miała inauguracja (1 XI, godz. 11.00-11.50) w Auli Uniwersytetu. Otworzyło ją odśpiewanie hymnu narodowego Gruzji z udziałem solisty. Po kolei przemawiali potem: prof. Roland Kopaliani (Rektor Uniwer-

2 International Multidisciplinary Conference „, The Humanities in the Age of Globalization", 1-2 November, Kutaisi 2019. Program, Kutaisi 2019, program gruzińsko-angielski, ss. 108 .

3 W skład Komitetu Organizacyjnego weszli tylko badacze gruzińscy, na czele z JM Rektorem: Luka Dvalishvili - Associate Pofesor, Department of Georgian Philology; Dean of the Faculty of Humanities, Akaki Tsereteli State University (ATSU); Inga Abramidze - Associate Professor, Department of History and Archeology, Head of Quality Assurance Service at the Faculty of Humanities, ATSU; Ekaterine Gachechiladze - Associate Professor, Department of Classical and Romance Philology, Deputy Dean of the Faculty of Humanities, ATSU; Nino Pkhakadze Associate Proffesor, Department of Georgian Philology, Deputy Dean of the Faculty of Humanities, ATSU; Ana Chikvaidze - Assistant Professor, Department of Slavic Philology, ATSU; Merab Tchumburidze - Associate Professor, Department of History and Archeology, ATSU; Shorena Barbakadze - Associate Professor, Department of Classical and Romance Philology, ATSU; Baia Koghuashvili - Associate Professor, Department of English Philology, ATSU; Sulkhan Kuprashvili - Professor, Department of History and Archeology, ATSU; Merab Maghradze - Associate Professor, Department of Pholosophy and Psychology, Head of Department, ATSU; Omar Nishnianidze - Professor, Department of History and Archeology, ATSU; Vera Otskheli - Professor, Department of Slavic Philology, ATSU; Nino Chikhladze - Professor, Department of Classical and Romance Philology, ATSU; Zviad Tskhvediani - Associate Professor, Department of Oriental Philology, ATSU; Irakli Tskhvediani - Professor, Department of English Philology, ATSU; Nato Tsuleiskiri - Associate Professor, Department of Georgian Philology, ATSU; Vakhtang Tevdoradze - Associate Professor, Department of Oriental Philology, ATSU; Ramaz Svanidze - Associate Professor, Department of German Philology, ATSU; Ramaz Khachapuridze - Associate Professor, Department of History and Archeology, ATSU; Ketevan Tchelidze - Head of the Programmic Assurance Department, Information Technologies Assurance Service, ATSU; Malkhaz Dograshvili - Director of the Publishing House; Nino Bakuradze - Coordinator of the Style and Editing. 
sytetu), prof. Luka Dvaishvili (Dziekan Wydziału Humanistycznego), Giorgi Tchigvaria (mer Kutaisi), Genadi Margvelashvili (gruziński Parlamentarny Zespół Edukacji i Nauki), prof. Giorgi Gavtadze (Wicerektor).

Częścią inauguracji była ceremonia nadania tytułu doktora honoris causa Uniwersytetu im. Akakiego Ceretelego przewodniczącemu weimarskiego Międzynarodowego Towarzystwa im. Goethego profesorowi Jochenowi Golzowi ${ }^{4}$. Niemcy są mocno obecne nawet w Gruzji, wspierają germanistykę bardzo rozwiniętą na uczelni, fundują stypendia dla młodych naukowców, szerząc przy okazji ,idee Goethego” w kraju bardzo przecież odmiennym niż Europa Zachodnia, toczącym w tej chwili „zamrożoną” wojnę z Rosją. Prof. Golz w dziękczynnym wystąpieniu akcentował $\mathrm{m}$. in. „za Goethem”, iż nauka nie ma narodowości, że trzeba szerzyć idee liberalizmu i humanizmu, co polegać ma na przykład na przyjmowaniu uchodźców. Zabrzmiało to zastanawiająco w tym miejscu, gdzie wciąż trwa walka o państwową i narodową niepodległość, toczą się wojny. Wygłoszone po niemiecku wystąpienie można było przeczytać na ekranie także w wersji angielskiej. Sama ceremonia nadania tytułu doktora honoris causa ma w Gruzji zupełnie inną oprawę: polega na wręczeniu niewielkich rozmiarów dyplomu i wysłuchaniu przemówienia nagrodzonego (bez pompy, tóg, długiej laudacji, rytuału).

Po przerwie odbyła się pierwsza część obrad, w czasie której wysłuchano wykładu Stefana Brendta (Uniwersytet w Grazu, Austria) pt. Daze of Doom Globalisation and the Transformation of National Paradigms in U.S. American Environmental Films. Obradami kierował dr Irakli Tskhvediani, amerykanista, który prowadził zagraniczną korespondencję całej Konferencji. Po przerwie obiadowej otwarto wystawę fotograficzną „Kutaisi - starożytne miasto europejskie". Z kolei w Auli badacze z Polski zaprezentowali wyniki badań archeologicznych w mieście. Wspólną pracę prof. Moniki Badury (UG, Gdańsk) i prof. Jacka Hamburga (Polsko-Gruzińskie Multidyscyplinarne Centrum Badawcze im. Profesora Krukowskiego) zaprezentował dr Grzegorz Skrzyński

4 Jochen Golz - niemiecki germanista, edytor urodzony w 1942 roku w Szczecinie. Od 1999 do 2019 był prezesem Towarzystwa im. Goethego w Weimarze. Autor licznych prac o twórczości Goethego, Jean-Paula, Schillera.

5 Tytuł wystapienia: Specialist Analyses of Materials from Archaeological Sites in the City of Kutaisi: First Research Results and Work Methodology. 
(Muzeum Ziemi PAN, Warszawa), na stałe mieszkający i prowadzący prace w Kutaisi. Część plenarną zakończył „workshop” Journalist-Respondent Relations: Contemporary Challenges, w którym wzięli udział badacze z miejscowej uczelni: Eka Pkhakadze i Gia Dvaishvili.

Dzień domknęła wycieczka o zmierzchu badaczy zagranicznych do monasterów w Gelati i Motsameta. Są to zabytki światowej klasy, będące jednak w stanie wymagającym natychmiastowych prac specjalistów. Pomimo deszczu i zmroku, klasztory wzbudziły zachwyt gości. Ostatnim akcentem dnia była uroczysta kolacja. Swym rozmachem przyćmiewała wszystko, co można spotkać w Europie, przypominając raczej gruzińską ucztę weselną, w czasie której przy piętrowo zastawionych stołach wznosi się toasty, słucha piosenek i pieśni wykonywanych na żywo, a także biesiadnie prowadzi rozmowy.

Już pierwszego dnia od 14.30 do 17.00 i drugiego (2 XI) dnia od 10.00 do 14.00 trwały prace w niezliczonych sekcjach kongresu. Ich ilość i rozmaitość daje wyobrażenie o jego wielkości, ale i pewnej, trudnej do zrozumienia dla nie-Gruzina, niekoherencji tematycznej. Wymieńmy tylko wybrane sekcje (podaję nazwy w wersji oryginalnej): Living in the Anthropocene: Responses in Biology, Philosophy, and Literature (przew. Brian Railsbach z Western Carolina University, USA); Identity of the Georgians: Language, Mythos, Culture, Literature (przew. Tariel Putkaradze i Eka Dadiani z Kutaisi); World History and Global Politics (przew. Vasil Kachatava z Tbilisi i Dato Tsuleiskiri z Kutaisi); Comparative Literature Studies: Literatury Process, Relations, Receptions, Influences (przew. Andrzej Baranow z Białegostoku i Vera Ostkheli z Kutaisi); Language and Discourse Analysis: Topical Issues of Psycholinguistics and Communicative Linguistica (przew. Ketevan Djachy z Uniwersytetu w Sewilii i Ekaterine Gachechiladze z Kutaisi); Philosophy, Politics and Sciences in the Age of Globalization (przew. Jarosław Ławski z Białegostoku i Mirian Ebanoidzie z Kutaisi); Gender in Language, Literatute and Culture (przew. Ketevan Antelava z Tbilisi i Mate Khvedelidze z Kutaisi); Modern art, Music, Cinema, Sculpture (przew. Zviad Dolidze i Lela Ochiauri z Tbilisi).

Podział uczestników na około 40 sekcji miał i swoje zalety, i wady. Do zalet należała pewna kameralność spotkań w małych grupach, do wad rozproszenie uczestników w sekcjach.

Drugi dzień rozpoczął się od obrad okrągłego stołu pt. Cities in the Global World: Urban Challenges and Prospects, poprowadzonego przez Nino Tval- 
tvadze z Rady Miejskiej Kutaisi. Potem uroczyście podpisano szereg umów dwustronnych między Uniwersytetem im. Akakiego Ceretelego a Uniwersytetem Teatru i Kina im. Szoty Rustaweliego w Tbilisi, Union of Cultural, Art and Edycational Instititions of Kutaisi, Wydziałem Sztuki i Nauk Humanistycznych Uniwersytetu w Grazu oraz Katolickim Uniwersytetem w Ružomberok na Słowacji.

Z kolei w godz. 11.00 - 11.45 wysłuchano „mono-performansu” Nikoloza Tsulukidze z Tbilisi pt. A Story of the Georgian Theatre. Z kolei prof. Johen Golz poprowadził godzinne (12.00 - 13.00) seminarium Understanding Goethean Concept of ,, World Literature”. Po lanczu goście zwiedzili Muzeum Historyczno-Etnograficzne w Kutaisi, gdzie wysłuchali prelekcji Omara Lanchovy 55 Years of Archeological Excavations in Kutaisi oraz byli świadkami prezentacji książki Revaza Kldiashvili The Queen of Byzantium. Konferencję zamknięto 2 listopada o godz. 16.00 .

Trudno - ze względu na rozmach przedsięwzięcia - stwierdzić, jak przebiegały poszczególne części kongresu. Do jego słabszych stron zaliczyć trzeba problemy komunikacyjne: w niektórych sekcjach badacze występujący po angielsku nie byli rozumiani przez badaczy gruzińskich, którzy mówili albo w swoim języku, albo dobrze komunikowali się po rosyjsku. Przy tak wielkiej sesji poślizgi czasowe powodowały duże kłopoty organizacyjne. Największym mankamentem konferencji był jednak wschodnioeuropejski „zwyczaj” zgłaszania i świadomego włączania do programu wystąpień, których nie ma się zamiaru wygłosić 6 . Z tego powodu w niektórych sekcjach obrady albo w ogóle się nie odbyły, albo nie było w nich połowy referentów. Jest to możliwe już tylko na wschód od Bugu. Wydaje się, że nawet imprezy z kongresowym rozmachem powinny mieć bardziej sprecyzowany, ograniczony zakres tematyczny - większy byłby z nich naukowy pożytek.

Z kolei do największych zalet tego zjazdu należało to, że organizatorzy umożliwili badaczom nie tylko wymianę myśli, lecz także autentyczne spotkania: ludzkie, międzykulturowe i badawcze. Tę cechę tracą już sformalizowane, „zimne”, a nawet bezduszne konferencje zachodnioeuropejskie. Ważnym ele-

6 Zgłoszenie (i przyjęcie) tematu wystąpienia na sesję, w której nie ma się zamiaru uczestniczyć, służy fikcyjnym rozliczeniom z uniwersytecką biurokracją: badacz może wykazać, potwierdzony zapisem w programie sesji, udział w wydarzeniu. 
mentem tego doświadczenia była możliwość spotkania z Gruzją: jej narodem, jego historią, kulturą, naturą. Dla Europejczyków i Amerykanów musiało to być spotkanie zaskakujące - z krajem będącym na skrzyżowaniu przednowoczesności z postnowoczesnością, dalekim od stereotypów, ambitnym i aż do zauroczenia gościnnym. Oczywiście, także niesłychanie ciekawym.

W Konferencji wzięła także udział spora grupa uczonych polskich. Prócz wymienionych archeologów Program przywołuje Jerzego Marka Nowakowskiego z Instytutu Orientalistyki UW (Generation post-political. Childern of Solidarity and Democratic Transformation) oraz czworo badaczy z Uniwersytetu w Białymstoku: dra hab. Andrzeja Baranowa, prof. UwB (On some Categories of Contemporary Comparative Studies in the Contect of PolishLithuanian Cultural Dialogue); dr hab. Annę Janicką, prof. UwB (Gender Studies in Central and Eastern Europe. Between the Methodology and the Ideology of Social Life), prof. Jarosława Lawskiego (Reform of Science in Central and Easten Europe: Directions, Threats); dra Pawła Wojciechowskiego (From Word to Cyberword).

Pobyt białostockich badaczy możliwy był dzięki zaproszeniu, jakie wystosowała prof. Vera Ozheli z Uniwersytetu w Kutaisi, wybitna badaczka gruzińsko-polskich związków kulturowych i literackich. Wprawdzie na miejscowej uczelni nie ma polonistyki, lecz Uczona dba tu o bodaj symboliczną obecność wątków polskich. Z Jej inicjatywy istnieje oznaczona tablicą „Sala im. Adama Mickiewicza", poety, który oddziaływał między innymi na takich gruzińskich twórców, jak Akaki Cereteli. W czasie sesji podjęto decyzję o organizacji w 2020 roku w Kutaisi i Białymstoku dwu międzynarodowych konferencji naukowych o polsko-gruzińskich relacjach w XIX i XX wieku (oba uniwersytety rozpoczęły prace nad zawarciem dwustronnej umowy długofalowej, która ma być sfinalizowana na początku 2020 roku).

Konferencję „The Humanities in the Age of Globalization” należy uznać za wydarzenie ze wszech miar interesujące - szczególnie dla badaczy zachodnioeuropejskich, polskich i amerykańskich. Pokazała ona silną obecność we

7 Po polsku zob. między innymi: V. Ozheli, Ilia Czawczawadze i krag literackich zwiazków polsko-gruzińskich w XIX wieku, „Wiek XIX” 2017; V. Ozheli, Reminiscencje poezji Adama Mickiewicza w prozie Akakiego Ceretelego, przeł. A. Pomianowska, „Slavica Occidentalis" 2007, t. 64; V. Ozheli, Polsko-gruzińskie związki literackie w XIX wieku (do 1917 r.), „Przegląd Humanistyczny” 1977, nr 2. 
współczesnym pejzażu kultury i nauki gruzińskiej takich kultur jak niemiecka, amerykańska, polska. Była też spotkaniem ze światem, w którym nauka ma nieco inne tradycje historyczne (Bizancjum, Europa, Azja), inaczej jest zorganizowana, a także ma odmienne rytuały, formy społecznego istnienia. Należy mieć nadzieję, iż oprócz księgi streszczeń i Programu ukaże się zbiór materiałów pokonferencyjnych.

Niezależnie od wszystkiego, dla gości Konferencji zaskoczeniem było Kutaisi - sprawnie funkcjonujące, uniwersyteckie, urocze miasto, z którego drogi prowadzą do najpiękniejszych miejsc w Gruzji: czarnomorskiego wybrzeża i w góry Kaukazu. 